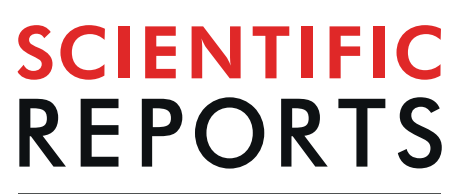

natureresearch

There are amendments to this paper

\title{
Gamma Attenuation Coefficients of Nano Cadmium Oxide/High density Polyethylene Composites
}

\author{
Ahmed M. El-Khatib ${ }^{1}$, Mahmoud I. Abbas $\mathbb{B D}^{1}$, Mohamed Abd Elzaher $\mathbb{D}^{2 *}$, \\ Mohamed S. Badawi ${ }^{3}$, Mahmoud T. Alabsy ${ }^{1}$, Gharam A. Alharshan ${ }^{4} \&$ Dalal A. Aloraini ${ }^{4}$
}

In the present work, high density polyethylene (HDPE) matrix mixed with micro-sized and nano-sized Cadmium oxide ( $\mathrm{CdO}$ ) particles of different concentrations were prepared by compression molding technique. The aim of the study is to investigate the effect of particle size and weight percentage of $\mathrm{CdO}$ particles on the gamma radiation shielding ability of CdO/HDPE composites. The mass attenuation coefficients of pure HDPE, micro-CdO/HDPE and nano-CdO/HDPE composites were evaluated at photon energies ranging from $59.53 \mathrm{keV}$ to $1408.01 \mathrm{keV}$ using standard radioactive point sources $\left[{ }^{241} \mathrm{Am},{ }^{133} \mathrm{Ba},{ }^{137} \mathrm{Cs},{ }^{60} \mathrm{Co}\right.$ and $\left.{ }^{152} \mathrm{Eu}\right]$. Adding micro and nano CdO particles to the HDPE matrix clearly increases the mass attenuation coefficients of the composites and the improvement is more significant at low $\gamma$-ray energies. The effect of particle size of $\mathrm{CdO}$ filler has an important role on the shielding ability of the composite. The experimental results reveal that, the composites filled with nano-CdO have better $\gamma$-radiation shielding ability compared to that filled with micro-CdO at the same weight fraction. A relative increase rate of about $16 \%$ is obtained with nano-CdO content of $40 \mathrm{wt} \%$ at $59.53 \mathrm{keV}$, which attributed to the higher probability of interaction between $\gamma$-rays and nanoparticles. From this study, it can be concluded that nano- $\mathrm{CdO}$ has a good performance shielding characteristic than micro-CdO in HDPE based radiation shielding material.

In recent times, researches on developing radiation protection and shielding materials acquired much interest. This is due to a wide spread of using different types of radiations in many areas and applications such as industries, medical care, agriculture, scientific research, etc. Accumulated doses from ionizing radiation have harmful effects on living and non-living matter. Therefore, it is necessary to provide shielding materials to attenuate radiations and protect personal life and other materials from hazardous radiations such as X-rays and $\gamma$-rays.

Common forms of radiation protecting materials are high density rigid materials such as concrete and lead products. Many dense materials like tungsten, bismuth, copper, steel, etc. can attenuate gamma and X-rays but lead predominant over them due to its low cost, high atomic number and high density. But lead shields have some shortages that limit its utilization such as heaviness, high toxicity, low mechanical and chemical stability, being rigid and poorly portable.

To overcome these shortcomings, polymer composites containing inorganic fillers, such as micro and nano particles, were widely investigated as alternative nuclear radiation shielding materials with advantages brought by their flexibility, chemical stability, light weight and low cost. Several polymers such as polyethylene ${ }^{1,2}$, recycled polyethylene ${ }^{3}$, epoxy $^{4}$, polyester ${ }^{5}$, styrene butadiene rubber ${ }^{6}$, ethylene-propylene-dine monomer $(\mathrm{EPDM})^{7}$, polyimide ${ }^{8}$, natural rubber ${ }^{9}$ and polystyrene ${ }^{10}$ were investigated as a nuclear protective matrixes. Metal oxides like $\mathrm{PbO}^{5}, \mathrm{PbWO}_{4}{ }^{7}, \mathrm{Sm}_{2} \mathrm{O}_{3}{ }^{8}, \mathrm{WO}_{3}{ }^{11}, \mathrm{Bi}_{2} \mathrm{O}_{3}{ }^{12}$ and $\mathrm{Gd}_{2} \mathrm{O}_{3}{ }^{13}$ have been used as fillers in the polymer matrix to provide radiation shield for use against $\mathrm{X}$-rays and $\gamma$-rays.

Making the fillers of the polymeric matrixes in the nano scale can dramatically enhance mechanical, thermal, electrical and optical properties of the polymeric composite ${ }^{14,15}$. Similarly, applying nano-scaled fillers into polymer matrices is also efficient in attenuating radiation ${ }^{16}$ since nanomaterials are more uniform and have less agglomeration in the composite and therefore can enhance the shielding ability of material ${ }^{17}$. Noor Azman et al. studied the size effect of $\mathrm{WO}_{3}$ particles dispersed in epoxy on the X-rays transmission ranging from $25 \mathrm{keV}$ to

${ }^{1}$ Physics Department, Faculty of Science, Alexandria University, 21511, Alexandria, Egypt. ${ }^{2}$ Department of Basic and Applied Science, Faculty of Engineering, Arab Academy for Science, Technology P.O 1129, Alexandria, Egypt. ${ }^{3}$ Department of Physics, Faculty of Science, Beirut Arab University, Beirut, Lebanon. ${ }^{4}$ Physics Department, Faculty of Science, Princess Nourah Bint Abdulrahaman University, Riyadh, Saudi Arabia. *email: mohzaher400@aast.edu 
$120 \mathrm{keV}$ and found that particle size effect was more significant at lower photon energy ${ }^{18}$. Ran Li et al. compared the radiation shielding properties of micro and nano gadolinium oxide $\left(\mathrm{Gd}_{2} \mathrm{O}_{3}\right)$ of different loadings dispersed in epoxy resin and at photon energies from $31 \mathrm{keV}$ to $356 \mathrm{keV}$ and concluded that nano- $\mathrm{Gd}_{2} \mathrm{O}_{3}$ composites were more effective to shield $\mathrm{X}$ and $\gamma$-rays than micro- $\mathrm{Gd}_{2} \mathrm{O}_{3}$ composites and an enhance effect of about $28 \%$ is obtained with nano- $\mathrm{Gd}_{2} \mathrm{O}_{3}$ content of $5 \mathrm{wt} \%$ at $59.53 \mathrm{KeV}^{13}$. Tekin et al. used MCNPX code to evaluate the mass attenuation coefficients of concrete doped by nano- $\mathrm{WO}_{3}$ and micro- $\mathrm{WO}_{3}$, and the results demonstrated that nano-sized $\mathrm{WO}_{3}$ had greater attenuation properties compared to micro-sized $\mathrm{WO}_{3}$ and the effect of particle size decrease as the energy of $\gamma$ ray increased ${ }^{19}$. M. Mahmoud et al. demonstrated that the composites-loaded-PbO NPs were the best shielding materials for $\gamma$-rays compared to that filled with bulk PbO and HDPE itself ${ }^{1}$.

As indicated from the literatures, employing of nano fillers in radiation shielding is a promising way to develop radiation protective materials. Therefore, there is a high demand for further investigating the size effect of fillers on gamma radiation shielding properties for different composite systems. Hence, the main purpose of this study is to investigate the effect of particle size and weight percentage of $\mathrm{CdO}$ particles on the gamma radiation shielding ability of $\mathrm{CdO} / \mathrm{HDPE}$ composites. To verify the size effect of CdO reinforced HDPE composite, micro and nano $\mathrm{CdO} / \mathrm{HDPE}$ composites were fabricated by compression molding procedure and characterized by a scanning electron microscope (SEM). The mass attenuation coefficients of pure HDPE, micro-CdO/HDPE and nano-CdO/HDPE composites were evaluated at photon energies ranging from $59.53 \mathrm{keV}$ to $1408.01 \mathrm{keV}$ by using HPGe scintillation detector. In addition, a comparative study was done to compare the radiation shielding ability of nano $\mathrm{CdO} / \mathrm{HDPE}$ versus micro $\mathrm{CdO} / \mathrm{HDPE}$ composites.

\section{Materials and Methods}

Materials. A commercial HDPE supplied by Sidpec Sidi Kerir Petrochemicals Company, HD5403EA grade with a melt flow index of $0.35 \mathrm{~g} / 10 \mathrm{~min}$ and density of $0.955 \mathrm{~g} / \mathrm{cm}^{3}$, was used as a polymer matrix in this investigation. $\mathrm{CdO}$ in powder form with particle size $0.95 \mu \mathrm{m}$ purchased from Loba Chemie Company and CdO-nano particles with average particle size $50 \mathrm{~nm}$ supplied by Nanotech Company (Egypt) were used as fillers.

Preparation of CdO/HDPE composites. Compression-molding technique was used to prepare the following samples: Pure HDPE, $10 \mathrm{wt} \%$, $20 \mathrm{wt} \%, 30 \mathrm{wt} \%$, and $40 \mathrm{wt} \%$ for micro CdO/HDPE and nano-CdO/HDPE composites. Firstly, HDPE was weighted sensitively by an electrical balance (Analytical Balance, GR200, Japan) with an accuracy $0.0001 \mathrm{~g}$ in a two roll mixer at $170^{\circ} \mathrm{C}$, which is above the melting temperature of HDPE, for $15 \mathrm{~min}$ with the rotator speed set as $40 \mathrm{rpm}$. After complete melting of pure HDPE, the filler was slowly added with continuous blending for $20 \mathrm{~min}$ to ensure a uniformly mixed composite.

Fully mixed sample was then put into a stainless steel frame of dimensions $\left(25 \times 25 \times 0.3 \mathrm{~cm}^{3}\right)$ for hot-pressing between two layers of thermal Teflon. The pressing was done by using a hydraulic press with an applied pressure $10 \mathrm{MPa}$ at $170^{\circ} \mathrm{C}$ for $10 \mathrm{~min}$. The pressure was then raised gradually up to $20 \mathrm{MPa}$ for another $10 \mathrm{~min}$. The sample was let in the press for 1 hour to cool down gradually by water at $20^{\circ} \mathrm{C}$. Finally, the produced sheet was taken out from the mould and cutted into circular samples of $8.4 \mathrm{~cm}$ in diameter to perform radiation-shielding tests.

Instrumentation. A scanning electron microscope (SEM) (JSM-6010LV, JEOL) was used to observe the shape of micro and nano $\mathrm{CdO}$ particles and cross section morphologies of $\mathrm{CdO} / \mathrm{HDPE}$ composites. To prepare the samples for SEM observation, the samples were coated with an ultrathin gold coating using a low-vacuum sputtering coating device (JEOL-JFC-1100E). The SEM images were obtained at magnification order of 5,000x at $20 \mathrm{KV}$.

The $\gamma$-ray spectrometric measurements were performed using $100 \mathrm{~cm}^{3}$ well calibrated Hyper pure germanium cylindrical detector (HPGe) from Canberra (Model GC1520) in conjunction with multichannel analyzer (MCA). The detector has a resolution of $1.85 \mathrm{keV}$ at $1.33 \mathrm{MeV}$ gamma ray peak ${ }^{60} \mathrm{Co}$ and relative efficiency of $15 \%$ in the energy range from $50 \mathrm{keV}$ to $10 \mathrm{MeV}^{20}$. The control of acquisition parameters and analysis of the collected spectra was carried out using ISO 9001 Genie 2000 data acquisition and analysis software fabricated by Canberra. The detector was housed in a lead shielding of $15 \mathrm{~cm}$ thickness to diminish the background radiations. The radiation measurements were done by using five radioactive sources of ${ }^{241} \mathrm{Am},{ }^{133} \mathrm{Ba},{ }^{137} \mathrm{Cs},{ }^{60} \mathrm{Co}$ and ${ }^{152} \mathrm{Eu}$ purchased from Physikalisch-Technische Bundesanstalt PTB in Braunschweig and Berlin. The emitted energies corresponding to these radioactive sources are listed in Table 1. The radioactive sources were placed at $508.67 \mathrm{~mm}$ from the detector surface to get very narrow beam and also to ignore the effect of detector dead time ${ }^{21}$. The produced composite of $2.5 \mathrm{~mm}$ thickness was placed on a holder between the standard gamma point source and detector. The setup and geometry of the measurement system is displayed in Fig. 1.

During measurement, the photon beam generated from the radioactive sources reacted with the sample and detected by HPGe crystal detector. Electrical signal generated by the detector was amplified and then analyzed using Genie 2000 software by choosing a narrow region symmetric with respect to the centroid of photon peak. The data acquisition time was high enough to give $<1 \%$ count error. The net area under the photo peak was determined and then the count rate $(\mathrm{N})$ was calculated.

The linear attenuation coefficient $\mu\left(\mathrm{cm}^{-1}\right)$ of each composite material can be obtained for $\gamma$-ray of appropriate energy according to Lambert- Beer law ${ }^{22}$ given by Eq. (1)

$$
\mu=\frac{1}{x} \ln \left[\frac{N_{(0)}}{N_{(x)}}\right]
$$

where $\mathrm{x}$ is the thickness of the sample, $\mathrm{N}_{(0)}$ and $\mathrm{N}_{(\mathrm{x})}$ are the detector count without and with the composite target. The linear attenuation coefficient $\mu$ can be evaluated as the slope of the best fitted line of a linear relation between $\ln \left[\frac{N_{(0)}}{N_{(x)}}\right]$ versus sample thickness $\mathrm{x}$. 


\begin{tabular}{|l|c|}
\hline source & Photon energy $(\mathbf{k e V})$ \\
\hline${ }^{241} \mathrm{Am}$ & 59.53 \\
\hline \multirow{2}{*}{${ }^{133} \mathrm{Ba}$} & 80.99 \\
\cline { 2 - 2 } & 356.01 \\
\hline${ }^{137} \mathrm{Cs}$ & 661.66 \\
\hline \multirow{2}{*}{${ }^{60} \mathrm{Co}$} & 1173.23 \\
\hline \multirow{5}{*}{${ }^{152} \mathrm{Eu}$} & 1332.5 \\
\hline \multirow{5}{*}{} & 121.78 \\
\cline { 2 - 2 } & 244.69 \\
\cline { 2 - 2 } & 344.28 \\
\cline { 2 - 2 } & 778.9 \\
\cline { 2 - 2 } & 964.13 \\
\cline { 2 - 2 } & 1408.01 \\
\hline
\end{tabular}

Table 1. Radioactive source and its corresponding photon energy.

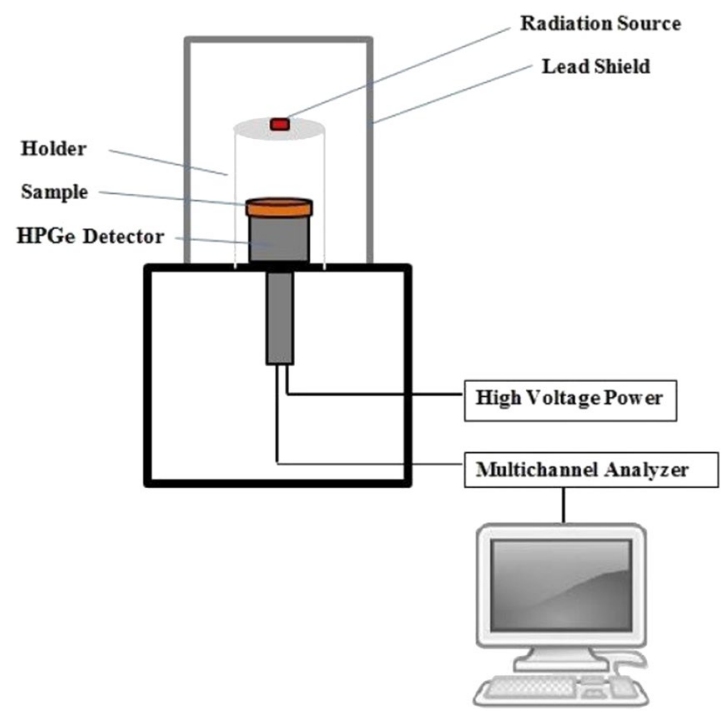

Figure 1. The experimental setup for examining $\gamma$-ray shielding property.

The mass attenuation coefficient $\mu_{\mathrm{m}}\left(\mathrm{cm}^{2} / \mathrm{g}\right)$, which is an important parameter for characterizing the interactions of $\gamma$-rays with matter, can be determined by dividing $\mu$ by the measured density $(\rho)$ of the sample ${ }^{23}$.

The average density of each composite sample was determined accurately by applying Archimedes technique according to ASTM D 792-91 ${ }^{24}$. For this purpose, a calibrated single pan electrical balance with accuracy $0.0001 \mathrm{~g}$ and three organic liquids such as ethanol, toluene and chlorobenzene were used.

\section{Results and Discussion}

Microstructure characterization. The SEM images of the microstructures of pure HDPE, micro CdO, CdO NPs, HDPE filled with $10 \mathrm{wt} \%$ micro CdO, $10 \mathrm{wt} \%$ nano CdO, $40 \mathrm{wt} \%$ micro CdO and $40 \mathrm{wt} \%$ nano CdO are displayed in Fig. 2. From Fig. 2b, it is noticed that micro particles of $\mathrm{CdO}$ are blocks in irregular large flaky shape with average particle size in the range from 0.58 to $0.95 \mu \mathrm{m}$. Figure $2 \mathrm{c}$ shows the presence of CdO nano particles with nearly a spherical shape and a particle size around $50 \mathrm{~nm}$. A clear variation can be noticed between the morphology of pure HDPE (Fig. 2a) and CdO/HDPE composites (Fig. 2d-g).

From Fig. $2 \mathrm{~d}-\mathrm{g}$, the SEM images of micro- and nano- CdO/HDPE composite samples with similar filler wt\% are compared. It is obvious that, in case of nano- $\mathrm{CdO} / \mathrm{HDPE}$ composites, $\mathrm{CdO}$ Nps are dispersed homogenously and well embedded in the HDPE matrix which may increase the interfacial adhesion between HDPE matrix and CdO NPs and this provide an interlocking structure for shielding. While, in case of micro- CdO/HDPE composites, large CdO particles are not well covered with the HDPE matrix and some of them are peeled off from the matrix due to weak interfacial adhesion which act as voids for shielding. Based on the SEM images, the distribution of nano particles should be more uniform than micro particles, so that higher shielding performance is expected by these nanocomposites. 

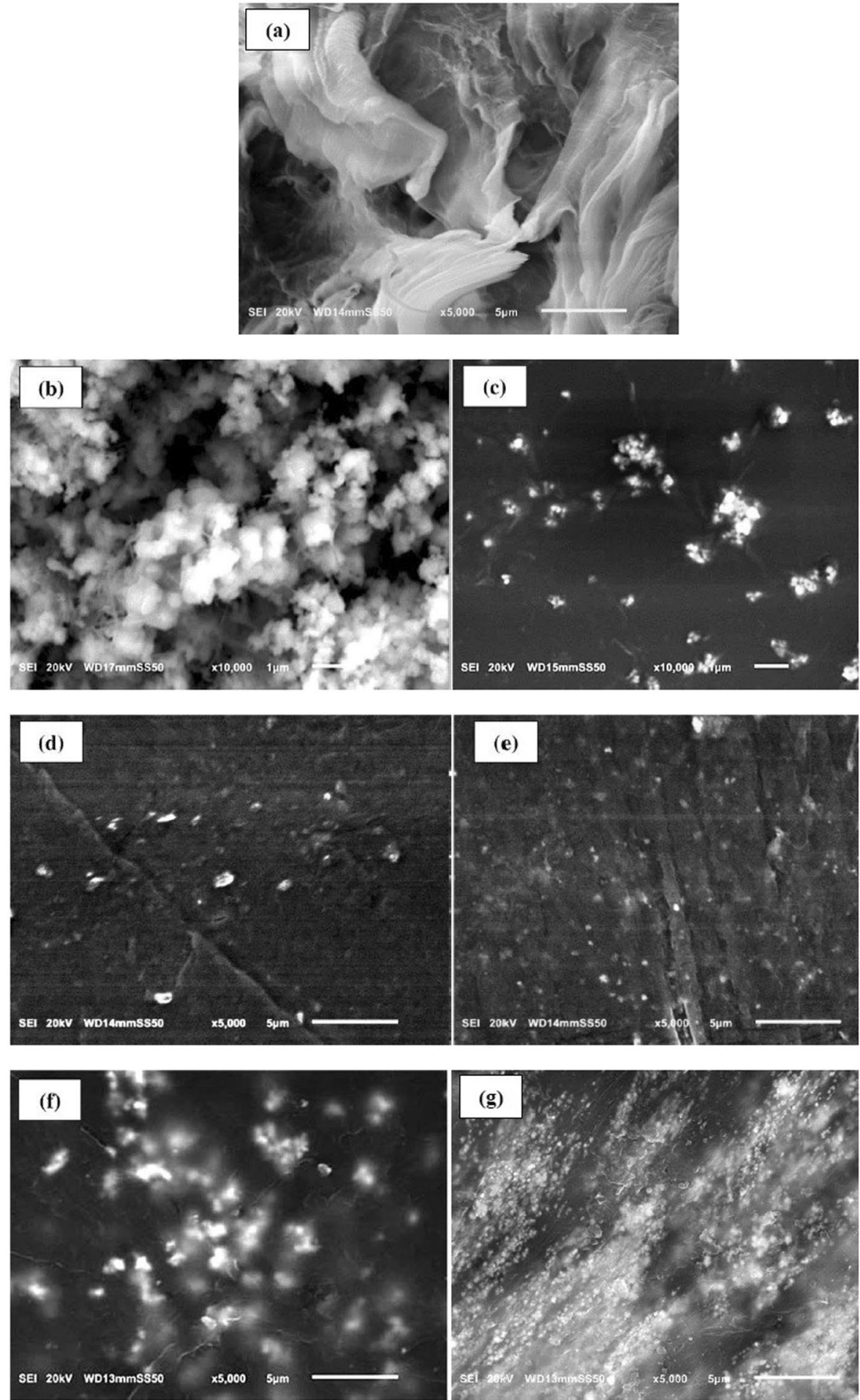

Figure 2. SEM images of (a) Pure HDPE, (b) micro CdO, (c) CdO NPs, (d) $10 \mathrm{wt} \%$ micro CdO composite, (e) $10 \mathrm{wt} \%$ nano CdO composite, (f) $40 \mathrm{wt} \%$ micro CdO composite, (g) $40 \mathrm{wt} \%$ nano CdO composite.

Gamma ray shielding properties of CdO/HDPE composites. Mass attenuation coefficient. The mass attenuation coefficient $\mu_{\mathrm{m}}$ is a widely used parameter in studying and comparing the shielding efficiency of different shielding materials. Table 2 lists out the measured values of mass attenuation coefficients, theoretical values of mass attenuation coefficients obtained using XCOM program and measured densities of pure HDPE, micro $\mathrm{CdO} / \mathrm{HDPE}$ and nano CdO/HDPE composites at 59.53, 80.99, 121.78, 244.69, 344.28, 356.01, 661.66, 778.9, $964.13,1173.23,1332.5$ and $1408.01 \mathrm{keV}$. The relative increase rate $\delta \%$ values between $\mu_{\mathrm{m}}$ of nanocomposites and microcomposites are also listed in Table 2 and calculated by Eq. (2) 


\begin{tabular}{|c|c|c|c|c|c|c|c|}
\hline \multirow[b]{2}{*}{ Sample } & \multirow[b]{2}{*}{ Energy $(\mathrm{keV})$} & \multicolumn{4}{|c|}{ Mass Attenuation Coefficient $\left(\mathrm{cm}^{2} \mathrm{~g}^{-1}\right)$} & \multicolumn{2}{|l|}{ Density } \\
\hline & & Nano CdO/HDPE & Micro CdO/HPE & $\delta \%$ & ХCOM & Nano CdO/HDPE & Micro CdO/HPE \\
\hline \multirow{12}{*}{ Pure HDPE 0 wt $\%$} & 59.53 & & 0.18892 & & 0.1888 & & \multirow{12}{*}{$0.944 \pm 0.014$} \\
\hline & 80.99 & & 0.17769 & & 0.1769 & & \\
\hline & 121.78 & & 0.16111 & & 0.1607 & & \\
\hline & 244.69 & & 0.13043 & & 0.1304 & & \\
\hline & 344.28 & & 0.11548 & & 0.1152 & & \\
\hline & 356.01 & & 0.11416 & & 0.1138 & & \\
\hline & 661.66 & & 0.08796 & & 0.08802 & & \\
\hline & 778.9 & & 0.08192 & & 0.08174 & & \\
\hline & 964.13 & & 0.07386 & & \begin{tabular}{|l|l|}
0.07387 \\
\end{tabular} & & \\
\hline & 1173.23 & & 0.0674 & & 0.06708 & & \\
\hline & 1332.5 & & 0.0631 & & 0.06283 & & \\
\hline & 1408.01 & & 0.06126 & & 0.06107 & & \\
\hline \multirow{12}{*}{$10 \mathrm{wt} \% \mathrm{CdO}$} & 59.53 & 0.79809 & 0.69191 & $15.35 \%$ & 0.6865 & \multirow{12}{*}{$1.11 \pm 0.012$} & \multirow{12}{*}{$1.039 \pm 0.031$} \\
\hline & 80.99 & 0.43917 & 0.38222 & $14.90 \%$ & 0.3823 & & \\
\hline & 121.78 & 0.25314 & 0.22171 & $14.18 \%$ & 0.2213 & & \\
\hline & 244.69 & 0.15302 & 0.13549 & $12.94 \%$ & 0.1357 & & \\
\hline & 344.28 & 0.13049 & 0.11583 & $12.65 \%$ & 0.1157 & & \\
\hline & 356.01 & 0.12824 & 0.11391 & $12.59 \%$ & 0.114 & & \\
\hline & 661.66 & 0.09638 & 0.08635 & $11.61 \%$ & 0.08654 & & \\
\hline & 778.9 & 0.08902 & 0.08007 & $11.18 \%$ & 0.08022 & & \\
\hline & 964.13 & 0.07964 & 0.07251 & $9.83 \%$ & 0.07239 & & \\
\hline & 1173.23 & 0.07237 & 0.06628 & $9.20 \%$ & 0.06568 & & \\
\hline & 1332.5 & 0.06669 & 0.06169 & $8.10 \%$ & 0.06151 & & \\
\hline & 1408.01 & 0.06451 & 0.05974 & $7.99 \%$ & 0.05979 & & \\
\hline \multirow{12}{*}{$20 \mathrm{wt} \% \mathrm{CdO}$} & 59.53 & 1.37488 & 1.1879 & $15.74 \%$ & 1.184 & \multirow{12}{*}{$1.239 \pm 0.024$} & \multirow{12}{*}{$1.145 \pm 0.0029$} \\
\hline & 80.99 & 0.68215 & 0.59226 & $15.18 \%$ & 0.5878 & & \\
\hline & 121.78 & 0.32326 & \begin{tabular}{|l|}
0.2827 \\
\end{tabular} & $14.35 \%$ & 0.2819 & & \\
\hline & 244.69 & 0.16076 & 0.14141 & $13.69 \%$ & 0.1411 & & \\
\hline & 344.28 & 0.13201 & 0.11657 & $13.25 \%$ & 0.1162 & & \\
\hline & 356.01 & 0.12907 & 0.11429 & $12.94 \%$ & 0.1143 & & \\
\hline & 661.66 & 0.09561 & 0.0851 & $12.35 \%$ & 0.08507 & & \\
\hline & 778.9 & 0.08856 & 0.07932 & $11.65 \%$ & 0.07871 & & \\
\hline & 964.13 & 0.07843 & 0.07082 & $10.74 \%$ & 0.07091 & & \\
\hline & 1173.23 & 0.07079 & 0.06422 & $10.23 \%$ & 0.06427 & & \\
\hline & 1332.5 & 0.0661 & 0.06052 & $9.23 \%$ & 0.0602 & & \\
\hline & 1408.01 & 0.06422 & 0.05901 & $8.83 \%$ & 0.05852 & & \\
\hline \multirow{12}{*}{$30 \mathrm{wt} \% \mathrm{CdO}$} & 59.53 & 1.93818 & 1.66864 & $16.15 \%$ & 1.682 & \multirow{12}{*}{$1.404 \pm 0.041$} & \multirow{12}{*}{$1.291 \pm 0.018$} \\
\hline & 80.99 & 0.91635 & 0.79184 & $15.73 \%$ & \begin{tabular}{|l|l|}
0.7933 \\
\end{tabular} & & \\
\hline & 121.78 & 0.39253 & 0.34174 & $14.86 \%$ & 0.3425 & & \\
\hline & 244.69 & 0.16731 & \begin{tabular}{|l|l|}
0.14662 \\
\end{tabular} & $14.11 \%$ & 0.1465 & & \\
\hline & 344.28 & 0.13266 & 0.11655 & $13.83 \%$ & \begin{tabular}{|l|l}
0.1167 \\
\end{tabular} & & \\
\hline & 356.01 & \begin{tabular}{|l|l|}
0.13083 \\
\end{tabular} & \begin{tabular}{|l|l|l}
0.11512 \\
\end{tabular} & $13.65 \%$ & \begin{tabular}{ll|}
0.1145 \\
\end{tabular} & & \\
\hline & 661.66 & \begin{tabular}{|l|}
0.09446 \\
\end{tabular} & \begin{tabular}{|l|}
0.08369 \\
\end{tabular} & $12.87 \%$ & \begin{tabular}{|l|}
0.08359 \\
\end{tabular} & & \\
\hline & 778.9 & \begin{tabular}{|l|}
0.08647 \\
\end{tabular} & 0.07706 & $12.20 \%$ & \begin{tabular}{|l|}
0.0772 \\
\end{tabular} & & \\
\hline & 964.13 & \begin{tabular}{|l|}
0.07739 \\
\end{tabular} & \begin{tabular}{|l|}
0.06937 \\
\end{tabular} & $11.56 \%$ & \begin{tabular}{|l|}
0.06943 \\
\end{tabular} & & \\
\hline & 1173.23 & \begin{tabular}{|l|l|}
0.07006 \\
\end{tabular} & \begin{tabular}{|l|}
0.06318 \\
\end{tabular} & $10.89 \%$ & 0.06287 & & \\
\hline & 1332.5 & \begin{tabular}{|l|l|}
0.06447 \\
\end{tabular} & \begin{tabular}{|l|}
0.05857 \\
\end{tabular} & $10.08 \%$ & \begin{tabular}{|l|l|}
0.05888 \\
\end{tabular} & & \\
\hline & 1408.01 & \begin{tabular}{|l|}
0.06309 \\
\end{tabular} & 0.05746 & $9.80 \%$ & 0.05725 & & \\
\hline
\end{tabular}




\begin{tabular}{|c|c|c|c|c|c|c|c|}
\hline \multirow[b]{2}{*}{ Sample } & \multirow[b]{2}{*}{ Energy $(\mathrm{keV})$} & \multicolumn{4}{|c|}{ Mass Attenuation Coefficient $\left(\mathrm{cm}^{2} \mathrm{~g}^{-1}\right)$} & \multicolumn{2}{|l|}{ Density } \\
\hline & & Nano CdO/HDPE & Micro CdO/HPE & $\delta \%$ & XCOM & Nano CdO/HDPE & Micro CdO/HPE \\
\hline \multirow{12}{*}{$40 \mathrm{wt} \% \mathrm{CdO}$} & 59.53 & 2.56203 & 2.19492 & $16.73 \%$ & 2.18000 & \multirow{12}{*}{$1.573 \pm 0.013$} & \multirow{12}{*}{$1.452 \pm 0.0036$} \\
\hline & 80.99 & 1.16549 & 1.00309 & $16.19 \%$ & 0.99870 & & \\
\hline & 121.78 & 0.46803 & 0.40572 & $15.36 \%$ & 0.40310 & & \\
\hline & 244.69 & 0.17545 & 0.15293 & $14.72 \%$ & 0.15180 & & \\
\hline & 344.28 & 0.13447 & 0.11765 & $14.29 \%$ & 0.11720 & & \\
\hline & 356.01 & 0.13203 & 0.11565 & $14.16 \%$ & 0.11480 & & \\
\hline & 661.66 & 0.09341 & 0.08223 & $13.60 \%$ & 0.08212 & & \\
\hline & 778.9 & 0.08526 & 0.07569 & $12.65 \%$ & 0.07568 & & \\
\hline & 964.13 & 0.07613 & 0.06799 & $11.97 \%$ & 0.06795 & & \\
\hline & 1173.23 & 0.06865 & 0.06156 & $11.50 \%$ & 0.06147 & & \\
\hline & 1332.5 & \begin{tabular}{|l|}
0.06369 \\
\end{tabular} & 0.05745 & \begin{tabular}{|l|l}
$10.86 \%$ \\
\end{tabular} & 0.05757 & & \\
\hline & 1408.01 & 0.0621 & \begin{tabular}{|l|}
0.05619 \\
\end{tabular} & $10.51 \%$ & 0.05598 & & \\
\hline
\end{tabular}

Table 2. Measured values of density, mass attenuation coefficients, relative increase rate and theoretical values using a WinXcom program of pure HDPE, micro Cdo/HDPE and nano CdO/HDPE composites.

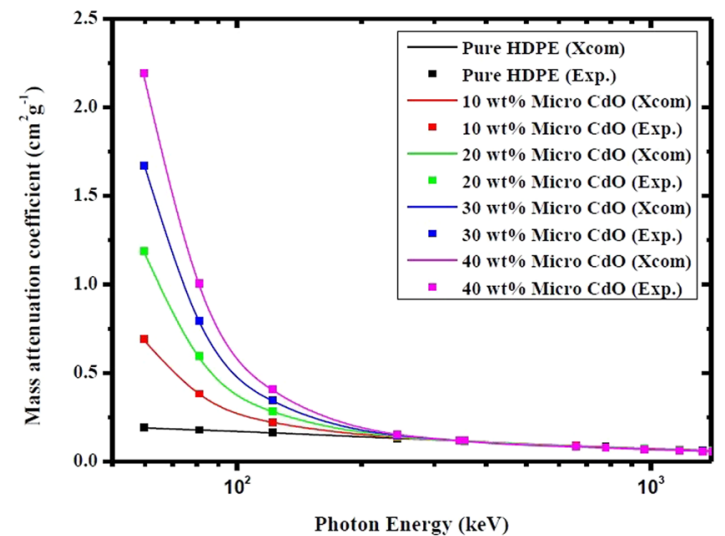

Figure 3. Experimental and theoretical values of mass attenuation coefficients of pure HDPE and micro CdO/ $\mathrm{HDPE}$ composites with different $\mathrm{CdO}$ concentrations as a function of photon energy.

$$
\delta=\frac{\mu_{\text {Nano }}-\mu_{\text {Micro }}}{\mu_{\text {Micro }}} \times 100
$$

Figure 3 depicts the experimental and theoretical values of mass attenuation coefficients of pure HDPE and micro CdO/HDPE composites filled by different CdO concentrations ( $10 \mathrm{wt} \%, 20 \mathrm{wt} \%, 30 \mathrm{wt} \%$ and $40 \mathrm{wt} \%)$ as a function of $\gamma$-ray energies listed in Table 1 . The theoretical values of mass attenuation coefficients were calculated using XCOM database ${ }^{25}$. It can be seen from Fig. 3 that there is a good agreement between the experimental and theoretical values of the mass attenuation coefficients for all composites which confirms a valid calibration of the experimental setup. Figure 4 presents the variations of the mass attenuation coefficient of nano CdO/HDPE composites with different $\mathrm{CdO}$ nanoparticles (NPs) concentrations as a function of photon energy.

As shown in Figs 3 and 4, the mass attenuation coefficient depends on the incident photon energy and the compositions of the shielding material. It is observed from Figs 3 and 4 that, at photon energy of range from $59.53 \mathrm{keV}$ to $121.78 \mathrm{keV}$ the mass attenuation coefficient increases significantly with increasing the concentrations of both micro- and nano-CdO in the composites and decreases sharply as the photon energy increases in this range. This is can be illustrated due to the three main interactions of photons with matter which are photoelectric effect, Compton scattering and pair production by which the incident photon dissipates its energy. At energies lower than $125 \mathrm{keV}$, the cross-sections for the photoelectric interactions are sufficiently high and photons are prone to be absorbed mainly by the photoelectric effect which depends on $\mathrm{Z}^{4} / \mathrm{E}^{3.5}$, where $\mathrm{Z}$ is the atomic number of the absorbing element and $\mathrm{E}$ is the photon energy $\mathrm{y}^{26,27}$. Therefore, by increasing the concentration of $\mathrm{CdO}$ in the polymer matrix, the mass attenuation coefficient increases owing to the element $\mathrm{Cd}$ with atomic number $(\mathrm{Z}=48)$ which has a strong photon absorption capability. On the other hand, because of the photoelectric cross section is inversely proportional to $\mathrm{E}^{3.5}, \mu_{\mathrm{m}}$ decreases rapidly with increasing the photon energy. 


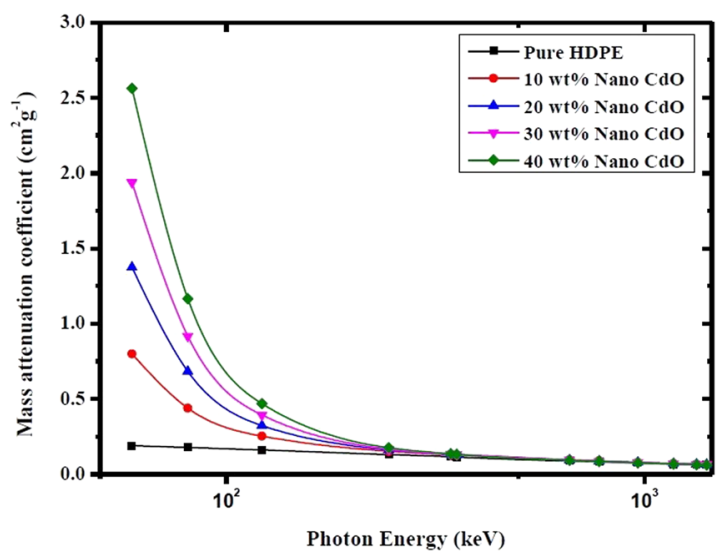

Figure 4. Mass attenuation coefficients of nano CdO/HDPE composites with different CdO NPs concentrations as a function of photon energy.

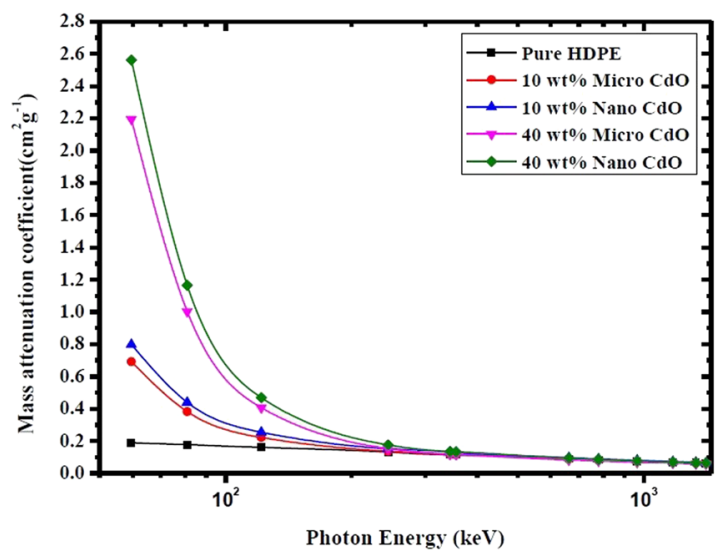

Figure 5. Comparison between mass attenuation coefficients of micro- and nano- CdO/HDPE composites at different $\mathrm{CdO}$ concentrations as a function of photon energy.

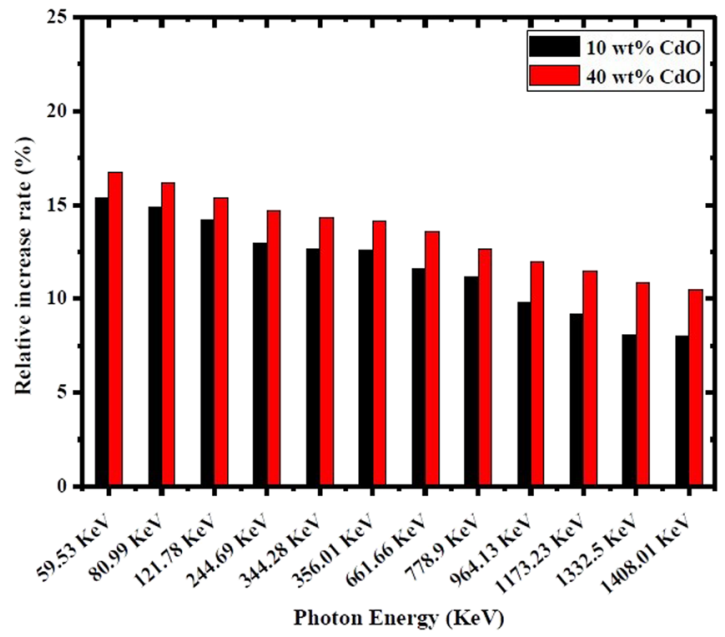

Figure 6. Relative increase rate versus photon energy at different weight fractions of CdO. 


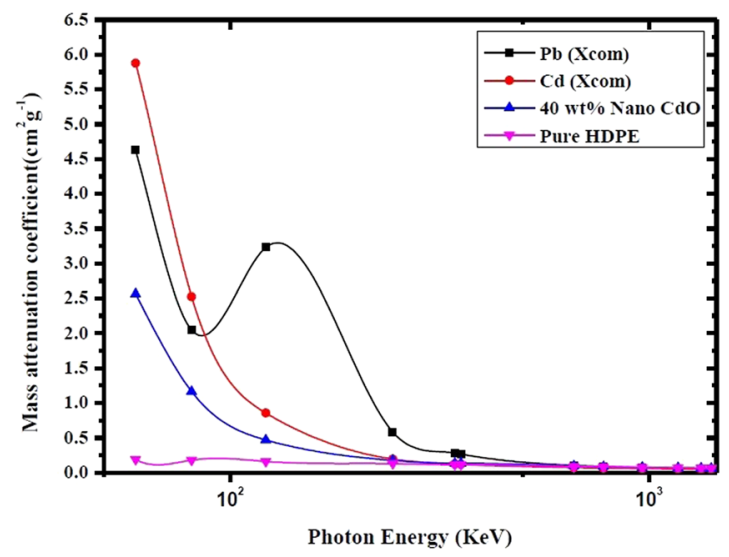

Figure 7. Comparison between mass attenuation coefficients of pure $\mathrm{Pb}$, pure $\mathrm{Cd}$, pure $\mathrm{HDPE}$ and $40 \mathrm{wt} \%$ nano $\mathrm{CdO}$ at different photon energies.

Moreover, as the photon energy increases to exceed $121.78 \mathrm{keV}$, the mass attenuation coefficient of each composite slightly decrease with increasing the photon energy and by increasing the filler wt $\%$, the values of $\mu_{\mathrm{m}}$ approximately have the same value over the certain energy range. This is because at this intermediate energy range, the effect of photoelectric absorption decreases and the Compton scattering become the dominant mechanism. The probability of Compton effect depends on the number of electrons per unit mass which is proportional to the ratio of the atomic number to the atomic weight $(\mathrm{Z} / \mathrm{M})$ and this ratio is approximately equal to 0.5 for all elements except for hydrogen and the heavy elements ${ }^{22}$. That is to say, at energies where the Compton scattering dominates, values of $\mu_{\mathrm{m}}$ tend to be nearly the same for all elements. As a result, increasing the filler content of $\mathrm{CdO}$ in polyethylene matrix in this energy range does not have a remarkable change in the value of $\mu_{\mathrm{m}}$ at certain energy.

As seen from Table 2, the obtained $\mu_{\mathrm{m}}$ values for nano composites are larger than those of micro composites at the same filler concentration and energy. To compare the contrast of $\mu_{\mathrm{m}}$ between micro- and nano- CdO/HDPE composites, the diagrams of $\mu_{\mathrm{m}}$ versus photon energy at different CdO particle concentrations are displayed in Fig. 5.

As evident from Fig. 5, over the entire range of photon energies, the curves for nano composites are all above the curves of micro composites. Thus, nano CdO/HDPE composites always have higher $\mu_{\mathrm{m}}$ than micro $\mathrm{CdO} /$ HDPE for the same wt $\%$ at all the investigated $\gamma$-ray energies. As the size of CdO particles decreases from micro to nano scale, the particles will be uniformly distributed over a lager surface area within polymer matrix, which will increase the interaction probability of incident photons to interact with nano-CdO particles in nano composites compared with micro composites ${ }^{28}$ and hence increase the chance of the photons to make more scattering processes. Hence, the photon will suffer multiple scattering processes until its energy be less than $200 \mathrm{keV}$, then it will be absorbed through photoelectric effect. Therefore, for the same chemical structure and weight fraction of the composite, nano-CdO particles show better attenuation performance than micro-CdO particles in HDPE based radiation shielding material.

In order to clarify the difference of shielding ability between nano and micro CdO/HDPE composites, the relative increase rate $\delta \%$ is introduced in Fig. 6 as a function of photon energy at different CdO particle concentrations.

It is clear from Fig. 6 that, with respect to photon energy, the relative increase rate $\delta \%$ increases with the increase of $\mathrm{CdO}$ concentration. As the photon energy increasing from $59.53 \mathrm{keV}$ to $1408.01 \mathrm{keV}$, the value of $\delta \%$ decreases, which is in agreement with the experimental results reported in reference ${ }^{1}$. This fact implies that the size effect becomes weak with the increase of photon energy, which is due to various photon interaction cross sections at different photon energies. At low photon energy, where the photoelectric dominates, the absorption ability depends on the atomic number $\mathrm{Z}$. Taking into account high $\mathrm{Z}$ of element cadmium in $\mathrm{CdO}$ particle and low $\mathrm{Z}$ of elements $\mathrm{C}$ and $\mathrm{H}$ in polyethylene matrix, the photoelectric absorption ability of $\mathrm{CdO}$ particle is much larger than that of polyethylene matrix, thus these particles play leading role in shielding radiation. Therefore, the particle size and concentration of CdO particles have outstanding effect on $\gamma$-ray shieling ability of composites. At higher energies, the probability of Compton scattering increases and its cross section may be considered as the main interaction which does not depend on $\mathrm{Z}$ but depends on the number of free electrons per unit mass, so low disparity of Compton scattering ability between $\mathrm{CdO}$ particles and polyethylene matrix is observed. So, the functional role of $\mathrm{CdO}$ particles reduces and the effect of particle size deceases.

The mass attenuation coefficients of the produced $40 \mathrm{wt} \%$ nano $\mathrm{CdO}$ composite was compared in Fig. 7 with the conventional shielding materials such as Lead, Cadmium and pure HDPE matrix at different photon energies. The highest radiation attenuation performance estimated was $55 \%$ of Lead and $44 \%$ of Cadmium at $59.53 \mathrm{keV}$. On the other hand, the composite had approximately 7.2 and 5.5 times lower density than Lead and Cadmium respectively and the performance was 13.56 times greater than the matrix material. Therefore this nano composite 


\begin{tabular}{|c|c|c|c|c|c|c|c|c|c|c|}
\hline \multirow[b]{2}{*}{$\begin{array}{l}\text { Energy } \\
(\mathrm{keV})\end{array}$} & \multicolumn{10}{|l|}{ HVL (cm) } \\
\hline & \begin{tabular}{|l} 
Pure \\
HDPE
\end{tabular} & $\begin{array}{l}10 \text { wt } \% \\
\text { micro CdO }\end{array}$ & $\begin{array}{l}10 \mathrm{wt} \% \\
\text { nano } \\
\text { CdO }\end{array}$ & $\begin{array}{l}20 \text { wt } \% \\
\text { micro CdO }\end{array}$ & $\begin{array}{l}20 \mathrm{wt} \% \\
\text { nano } \\
\mathrm{CdO}\end{array}$ & $\begin{array}{l}30 \text { wt } \% \\
\text { micro } \\
\text { CdO }\end{array}$ & $\begin{array}{l}30 \mathrm{wt} \% \\
\text { nano } \\
\text { CdO }\end{array}$ & $\begin{array}{l}40 w t \% \\
\text { micro } \\
\text { CdO }\end{array}$ & $\begin{array}{l}40 \mathrm{wt} \% \\
\text { nano } \\
\mathrm{CdO}\end{array}$ & Pure lead \\
\hline 59.53 & 3.88666 & 0.96419 & 0.78244 & 0.50961 & 0.4069 & 0.32176 & 0.25472 & 0.21749 & 0.17199 & 0.01321 \\
\hline 80.99 & 4.13227 & 1.74539 & 1.4219 & 1.02213 & 0.82012 & 0.67805 & 0.53876 & 0.4759 & 0.37809 & 0.02989 \\
\hline 121.78 & 4.55748 & 3.00897 & 2.4668 & 2.14139 & 1.73062 & 1.57109 & 1.25772 & 1.17662 & 0.94151 & 0.01892 \\
\hline 244.69 & 5.62939 & 4.92397 & 4.08094 & 4.28106 & 3.48 & 3.66202 & 2.95082 & 3.12144 & 2.51158 & 0.10492 \\
\hline 344.28 & 6.35857 & 5.75943 & 4.78561 & 5.19328 & 4.23788 & 4.60685 & 3.7214 & 4.05753 & 3.27698 & 0.21591 \\
\hline 356.01 & 6.43173 & 5.85676 & 4.86932 & 5.29686 & 4.33434 & 4.66389 & 3.77346 & 4.1276 & 3.33757 & 0.23014 \\
\hline 661.66 & 8.34815 & 7.72567 & 6.47922 & 7.11358 & 5.85132 & 6.41565 & 5.22657 & 5.80525 & 4.71721 & 0.59057 \\
\hline 778.9 & 8.9635 & 8.3321 & 7.01495 & 7.6321 & 6.31684 & 6.967 & 5.70961 & 6.30707 & 5.16811 & 0.70721 \\
\hline 964.13 & 9.94187 & 9.20025 & 7.84103 & 8.54787 & 7.13335 & 7.73947 & 6.37905 & 7.02135 & 5.78829 & 0.86997 \\
\hline 1173.23 & 10.8934 & 10.06604 & 8.62875 & 9.42673 & 7.90272 & 8.49862 & 7.04704 & 7.75419 & 6.41922 & 1.02626 \\
\hline 1332.5 & 11.63584 & 10.81353 & 9.36306 & 10.00357 & 8.46334 & 9.1674 & 7.65739 & 8.30912 & 6.91833 & 1.12278 \\
\hline 1408.01 & 11.98594 & 11.16719 & 9.67947 & 10.25821 & 8.71116 & 9.34412 & 7.8251 & 8.49549 & 7.0961 & 1.16073 \\
\hline
\end{tabular}

Table 3. HVL values of CdO/HDPE composites and pure lead at different $\gamma$-ray energies.

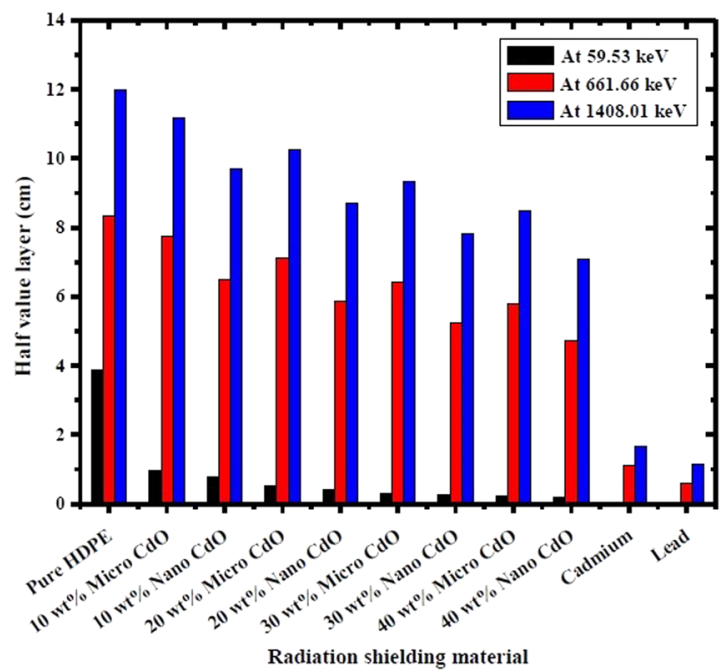

Figure 8. Half value layers of the composites at different photon energies.

and light weight material is promising to be used as absorber for low energy photons (e.g. diagnostic X-rays) and could be an alternative to lead shielding.

Half value layer (HVL). Half value layer (HVL), an important parameter in designing an appropriate radiation shielding, is defined as the thickness of the radiation shielding material required to attenuate the radiation level to $50 \%$ of its initial value and is computed using Eq. $(3)^{23}$

$$
H V L=\frac{\ln 2}{\mu}
$$

where $\mu\left(\mathrm{cm}^{-1}\right)$ is the linear attenuation coefficient of the material.

The calculated HVL of the CdO/HDPE composites and pure lead at different gamma ray energies are displayed in Table 3. According to the results, the HVL values of the investigated composites are much lower than pure HDPE especially at lower energies and high filler concentrations which leads to better shielding properties of the composites versus pure HDPE. Figure 8 depicts the HVL of CdO/HDPE composites as well as conventional shielding materials such as lead and cadmium for comparison at photon energies of $59.53 \mathrm{keV}, 661.66 \mathrm{keV}$ and $1408.01 \mathrm{keV}$. It is evident that, by increasing the photon energy, the HVL values increase where more thickness of the absorbing material is required to diminish the intensity of the incident $\gamma$-ray to one half of its initial value. By increasing the $\mathrm{CdO}$ concentration, the HVL values decrease which is due to the increase in the linear attenuation coefficients with increasing the CdO loading in the composites. Further, it is found that for the same filler wt\%, the HVL values for the nano-CdO/HDPE composites are much lower than that of micro-CdO/HDPE composites at all the investigated $\gamma$-ray energies which leads to the higher shielding performance of the nanocomposites, which consistent with the former analysis. In order to explore the effectiveness of the investigated composites 


\begin{tabular}{|c|c|c|c|c|c|c|c|c|c|}
\hline \multirow{3}{*}{$\begin{array}{l}\text { Energy } \\
(\mathrm{keV})\end{array}$} & \multicolumn{9}{|c|}{$\mathrm{HVL}_{\text {composite }} / \mathrm{HVL}_{\text {lead }}$} \\
\hline & \multirow{2}{*}{$\begin{array}{l}\text { Pure } \\
\text { HDPE }\end{array}$} & \multicolumn{2}{|c|}{$10 w t \% \mathrm{CdO}$} & \multicolumn{2}{|c|}{20 wt $\%$ CdO } & \multicolumn{2}{|c|}{30 wt $\%$ CdO } & \multicolumn{2}{|c|}{$40 w t \% \mathrm{CdO}$} \\
\hline & & micro & nano & micro & nano & micro & nano & micro & nano \\
\hline 59.53 & 294.22 & 72.99 & 59.23 & 38.58 & 30.8 & 24.36 & 19.28 & 16.46 & 13.02 \\
\hline 80.99 & 138.25 & 58.39 & 47.57 & 34.2 & 27.44 & 22.68 & 18.02 & 15.92 & 12.65 \\
\hline 121.78 & 240.88 & 159.04 & 130.38 & 113.18 & 91.47 & 83.04 & 66.48 & 62.19 & 49.76 \\
\hline 244.69 & 53.65 & 46.93 & 38.9 & 40.8 & 33.17 & 34.9 & 28.12 & 29.75 & 23.94 \\
\hline 344.28 & 29.45 & 26.68 & 22.16 & 24.05 & 19.63 & 21.34 & 17.24 & 18.79 & 15.18 \\
\hline 356.01 & 27.95 & 25.45 & 21.16 & 23.02 & 18.83 & 20.27 & 16.4 & 17.94 & 14.5 \\
\hline 661.66 & 14.14 & 13.08 & 10.97 & 12.05 & 9.91 & 10.86 & 8.85 & 9.83 & 7.99 \\
\hline 778.9 & 12.67 & 11.78 & 9.92 & 10.79 & 8.93 & 9.85 & 8.07 & 8.92 & 7.31 \\
\hline 964.13 & 11.43 & 10.58 & 9.01 & 9.83 & 8.2 & 8.9 & 7.33 & 8.07 & 6.65 \\
\hline 1173.23 & 10.61 & 9.81 & 8.41 & 9.19 & 7.7 & 8.28 & 6.867 & 7.56 & 6.25 \\
\hline 1332.5 & 10.36 & 9.63 & 8.34 & 8.91 & 7.54 & 8.16 & 6.82 & 7.4 & 6.16 \\
\hline 1408.01 & 10.33 & 9.62 & 8.34 & 8.84 & 7.5 & 8.05 & 6.74 & 7.32 & 6.11 \\
\hline
\end{tabular}

Table 4. Ratio of HVL values of CdO/HDPE composites to HVL of pure lead at different $\gamma$-ray energies.

as shielding materials, the ratio of HVL of CdO/HDPE composites to that of pure lead is presented in Table 4 . It is obvious that $1.72 \mathrm{~mm}$ of $40 \mathrm{wt} \%$ nano $\mathrm{CdO}$ composite is equivalent to $0.13 \mathrm{~mm}$ of lead shield at $59.53 \mathrm{keV}$ which is 13.02 times the thickness of lead. However, at higher energy of $1408.01 \mathrm{keV}, 70.96 \mathrm{~mm}$ of this composite is equivalent to $11.61 \mathrm{~mm}$ of lead which is only 6.11 times the thickness of lead. Therefore, this nano composite as light weight material is promising to be used as absorber for low energy photons (e.g. diagnostic X-rays) and could be an alternative to lead shielding.

\section{Conclusions}

In this study, the effects of particle size and weight percentage of $\mathrm{CdO}$ particles on gamma radiation shielding properties of $\mathrm{CdO} / \mathrm{HDPE}$ composites were investigated by measuring the mass attenuation coefficients at different photon energies. The composites were fabricated by compression molding technique and their morphological structures were characterized by SEM. According to the acquired SEM images, the distribution of nano particles is more uniform than micro particles leading to a strong interfacial adhesion between HDPE matrix and CdO NPs and this provide an interlocking structure for shielding.

The experimental results demonstrated that size and concentration of the CdO particles affected the $\gamma$-radiation shielding ability of HDPE at all the investigated energies. The composites filled with nano-CdO have greater mass attenuation coefficients compared to that filled with micro-CdO at the same weight fraction. That is attributed to the homogenous distribution of nano CdO particles within HDPE matrix with high electron density, which result in higher interaction probability between incident photons and CdO NPs in nano composites compared to micro composites. A relative increase rate of about $16.73 \%$ is obtained with nano-CdO content of $40 \mathrm{wt} \%$ at $59.53 \mathrm{KeV}$. It can be concluded that nano-CdO reinforced HDPE composite is a promising novel shielding material to be used to reduce radiation dose.

Received: 16 May 2019; Accepted: 10 October 2019;

Published: 5 November 2019

\section{References}

1. Mahmoud, M. E. et al. Fabrication, characterization and gamma rays shielding properties of nano and micro lead oxide-dispersedhigh density polyethylene composites. Radiat. Phys. Chem. 145, 160-173 (2018).

2. Shin, J. W. et al. Polyethylene/boron-containing composites for radiation shielding. Thermochim. Acta 585, 5-9 (2014).

3. Mahmoud, M. E. et al. Recycled high-density polyethylene plastics added with lead oxide nanoparticles as sustainable radiation shielding materials. J. Clean. Prod. 176, 276-287 (2018).

4. Chang, L. et al. Preparation and characterization of tungsten/epoxy composites for $\gamma$-rays radiation shielding. Nucl. Instruments Methods Phys. Res. Sect. B Beam Interact. with Mater. Atoms 356, 88-93 (2015).

5. Harish, V., Nagaiah, N., Prabhu, T. N. \& Varughese, K. T. Preparation and characterization of lead monoxide filled unsaturated polyester based polymer composites for gamma radiation shielding applications. J. Appl. Polym. Sci. 112, 1503-1508 (2009).

6. Abdel-Aziz, M. M., Badran, A. S., Abdel-Hakem, A. A., Helaly, F. M. \& Moustafa, A. B. Styrene-butadiene rubber/lead oxide composites as gamma radiation shields. J. Appl. Polym. Sci. 42, 1073-1080 (1991).

7. Huang, W. et al. Preparation and characterization of $\gamma$-ray radiation shielding $\mathrm{PbWO}_{4} / \mathrm{EPDM}$ composite. J. Radioanal. Nucl. Chem. 309, 1097-1103 (2016).

8. Wang, P., Tang, X., Chai, H., Chen, D. \& Qiu, Y. Design, fabrication, and properties of a continuous carbon-fiber reinforced $\mathrm{Sm}_{2} \mathrm{O}_{3} /$ polyimide gamma ray/neutron shielding material. Fusion Eng. Des. 101, 218-225 (2015).

9. Gwaily, S. E., Madani, M. \& Hassan, H. H. Lead-Natural rubber composites as gamma radiation shields. II: High concentration. Polym. Compos. 23, 495-499 (2002).

10. Pavlenko, V. I., Lipkanskii, V. M. \& Yastrebinskii, P. N. Calculations of the Passage of Gamma-Quanta through a Polymer RadiationProtective Composite. J. Eng. Phys. Thermophys. 77, 11-14 (2004).

11. Yu, D. et al. Effects of $\mathrm{WO}_{3}$ particle size in $\mathrm{WO}_{3}$ /epoxy resin radiation shielding material. Chinese Phys. Lett. 29, 108102 (2012).

12. Noor Azman, N. Z. et al. Characteristics of X-ray attenuation in electrospun bismuth oxide/polylactic acid nanofibre mats. J. Synchrotron Radiat. 20, 741-748 (2013). 
13. Li, R. et al. Effect of particle size on gamma radiation shielding property of gadolinium oxide dispersed epoxy resin matrix composite. Mater. Res. Express 4, 35035 (2017).

14. Amin, G. A. M. \& Abd-El Salam, M. H. Optical, dielectric and electrical properties of PVA doped with Sn nanoparticles. Mater. Res. Express 1, 25024 (2014)

15. Sharma, M. et al. Flexible EMI shielding materials derived by melt blending PVDF and ionic liquid modified MWNTs. Mater. Res. Express 1, 35003 (2014).

16. Bai, X.-M., Voter, A. F., Hoagland, R. G., Nastasi, M. \& Uberuaga, B. P. Efficient annealing of radiation damage near grain boundaries via interstitial emission. Science (80-.). 327, 1631-1634 (2010).

17. El Haber, F. \& Froyer, G. Transparent polymers embedding nanoparticles for X-rays attenuation. J. Univ. Chem. Technol. Metall. 43, 221 (2008).

18. Azman, N. Z. N., Siddiqui, S. A., Hart, R. \& Low, I.-M. Effect of particle size, filler loadings and x-ray tube voltage on the transmitted $\mathrm{X}$-ray transmission in tungsten oxide-epoxy composites. Appl. Radiat. Isot. 71, 62-67 (2013).

19. Tekin, H. O., Singh, V. P. \& Manici, T. Effects of micro-sized and nano-sized $\mathrm{WO}_{3}$ on mass attenauation coefficients of concrete by using MCNPX code. Appl. Radiat. Isot. 121, 122-125 (2017).

20. EL-Khatib, A. M. et al. Computation of the full energy peak efficiency of an HPGE detector using a new compact simulation analytical approach for spherical sources. J. Eng. Sci. Technol. 8, 623-638 (2013).

21. El-Khatib, A. M. et al. Full-Energy peak efficiency of an $\mathrm{NaI}$ (Tl) detector with coincidence summing correction showing the effect of the source-to-detector distance. Chinese J. Phys. 55, 478-489 (2017).

22. Biswas, R., Sahadath, H., Mollah, A. S. \& Huq, M. F. Calculation of gamma-ray attenuation parameters for locally developed shielding material: Polyboron. J. Radiat. Res. Appl. Sci. 9, 26-34 (2016).

23. Harish, V., Nagaiah, N. \& Kumar, H. G. Lead oxides filled isophthalic resin polymer composites for gamma radiation shielding applications (2012).

24. ASTM. Standard Methods for Density and Specific Gravity (Relative Density) of Plastics by Displacement (D 792-91). in (1997).

25. Berger, M. J. et al. XCOM: Photon cross sections database, 2010, http//www nist gov/pml/data/xcom (2010).

26. Knoll, G. F. Radiation detection and measurement. (John Wiley \& Sons, 2010).

27. Ahmed, S. N. Physics and engineering of radiation detection. (Academic Press, 2007).

28. Hassan, H. E., Badran, H. M., Aydarous, A. \& Sharshar, T. Studying the effect of nano lead compounds additives on the concrete shielding properties for $\gamma$-rays. Nucl. Instruments Methods Phys. Res. Sect. B Beam Interact. with Mater. Atoms 360, 81-89 (2015).

\section{Acknowledgements}

This research project was funded by the Deanship of Scientific Research, Princess Nourah bint Abdulrahman University, through the Research Funding Program No. (236-ص-39).

\section{Author contributions}

Ahmed M. El-Khatib, Mahmoud T. Alabsy and Mohamed Abd Elzaher wrote the main manuscript text. Mahmoud I. Abbas, and Mohamed S. Badawi prepared and drown all figures. Gharam A. Alharshan, and Dalal A. Aloraini Contributing in preparing the used composites materials. All authors reviewed and revised the manuscript.

\section{Competing interests}

The authors declare no competing interests.

\section{Additional information}

Correspondence and requests for materials should be addressed to M.A.E.

Reprints and permissions information is available at www.nature.com/reprints.

Publisher's note Springer Nature remains neutral with regard to jurisdictional claims in published maps and institutional affiliations.

(c) (i) Open Access This article is licensed under a Creative Commons Attribution 4.0 International (c) License, which permits use, sharing, adaptation, distribution and reproduction in any medium or format, as long as you give appropriate credit to the original author(s) and the source, provide a link to the Creative Commons license, and indicate if changes were made. The images or other third party material in this article are included in the article's Creative Commons license, unless indicated otherwise in a credit line to the material. If material is not included in the article's Creative Commons license and your intended use is not permitted by statutory regulation or exceeds the permitted use, you will need to obtain permission directly from the copyright holder. To view a copy of this license, visit http://creativecommons.org/licenses/by/4.0/.

(C) The Author(s) 2019, corrected publication 2021 